\title{
Severe hepatic encephalopathy and decrease in enhancement of hepatocellular carcinoma treated with sorafenib
}

\author{
Takefumi Kimura, Takeji Umemura, Tetsuya Ichijo \\ Nobuvoshi Yamamura, Eiii Tanaka
}

\section{CASE REPORT}

Sorafenib (Nexavar; Bayer Pharmaceuticals Group, Montville, NJ) is an oral multikinase inhibitor recently licensed in Japan for the treatment of advanced hepatocellular carcinoma (HCC) in May 2009. Although the most frequently reported adverse events of sorafenib have been fatigue, anorexia, diarrhea, rash, and hand-foot skin disease, [1] we here report a patient who developed severe hepatic encephalopathy that accompanied marked improvement of HCC after only three days of treatment with sorafenib.

A 79-year-old woman with hepatitis $\mathrm{C}$ virus-related cirrhosis (Child-Pugh A; 5: prothrombin 78\%; bilirubin $1.7 \mathrm{mg} / \mathrm{dl}$; albumin $3.6 \mathrm{~g} / \mathrm{dl}$; no ascites or encephalopathy) had progressive multinodular HCC despite three earlier rounds of transcatheter arterial chemoembolization (TACE). She had received a blood transfusion during a partial gastrectomy for a gastric ulcer at 36 years of age. There were no extrahepatic manifestations of hepatitis $\mathrm{C}$ at presentation, nor had she been taking any medications. Ammonia level was $60 \mu \mathrm{g} / \mathrm{dL}$ (normal, <70 $\mu \mathrm{g} / \mathrm{dL}$ ). Serum alpha fetoprotein and des- $\gamma$-carboxy prothrombin were

Takefumi Kimura, 2, Takeji Umemura², Tetsuya Ichijo², Nobuyoshi Yamamura ${ }^{1}$, Eiji Tanaka ${ }^{2}$

Affiliations: ${ }^{1}$ Department of Gastroenterology, Suwa Red Cross Hospital, Suwa, Japan; ${ }^{2}$ Department of Medicine, Shinshu University School of Medicine, Matsumoto, Japan.

Corresponding Author: Takeji Umemura, Department of Medicine, Shinshu University School of Medicine, 3-1-1 Asahi, Matsumoto, Japan - 390-8621; Phone: +81-26337-2634; Fax: +81-263-32-9412;

Email: tumemura@shinshu-u.ac.jp

Received: 2 September 2010

Accepted: 19 October 2010

Published: 19 December 2010
$146 \mathrm{ng} / \mathrm{mL}$ and $1250 \mathrm{mAU} / \mathrm{mL}$, respectively. A computed tomography (CT) scan revealed multiple carcinomas, including a hilus tumor of maximum 6.5 $\mathrm{cm}$ diameter with a portal vein tumor thrombus (Figure 1). Metastasis was not evident. Sorafenib at a daily dosage of 800mg was started in September 2009. After 3 days of treatment, the patient suddenly experienced disturbed consciousness and fell into a coma, which was suggestive of hepatic encephalopathy. Her serum ammonia level was high at $177 \mu \mathrm{g} / \mathrm{dL}$ (normal $<60 \mu \mathrm{g} / \mathrm{dL}$ ). CT scan and magnetic resonance imaging of the brain showed no cerebrovascular disorder or reversible posterior leukoencephalopathy syndrome [2]. An electroencephalogram was not performed. Surprisingly, a CT scan of the abdomen showed a marked decrease in tumor enhancement, which indicated diminished blood flow (Figure 2).

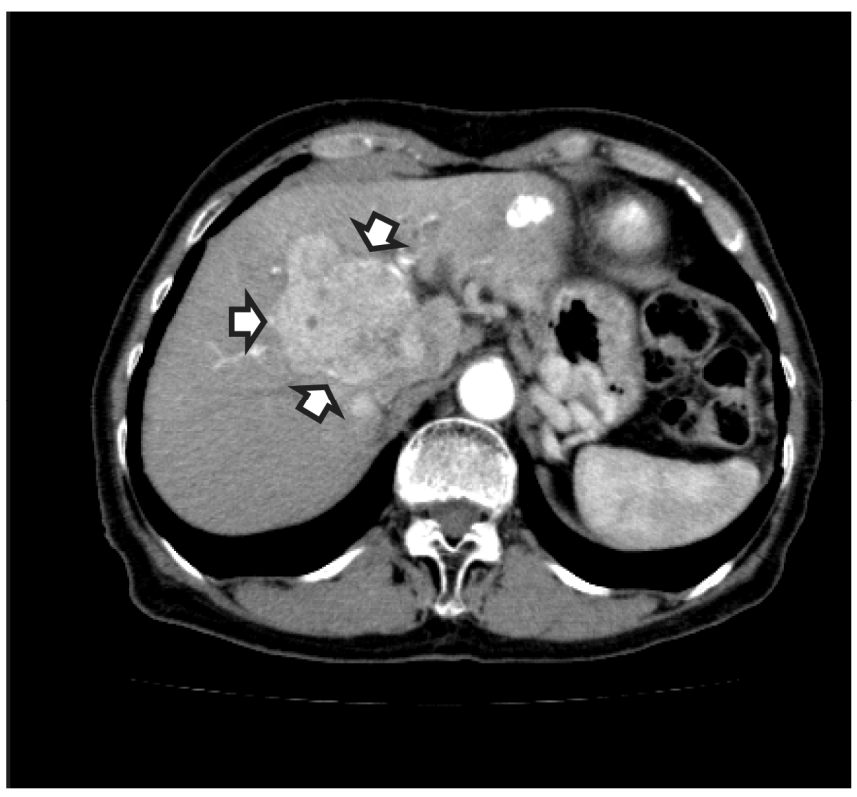

Figure 1: An enhanced computed tomography (CT) scan revealed multiple carcinomas (arrows), including a maximum $6.5 \mathrm{~cm}$ at hilus tumor with portal vein tumor thrombus. 


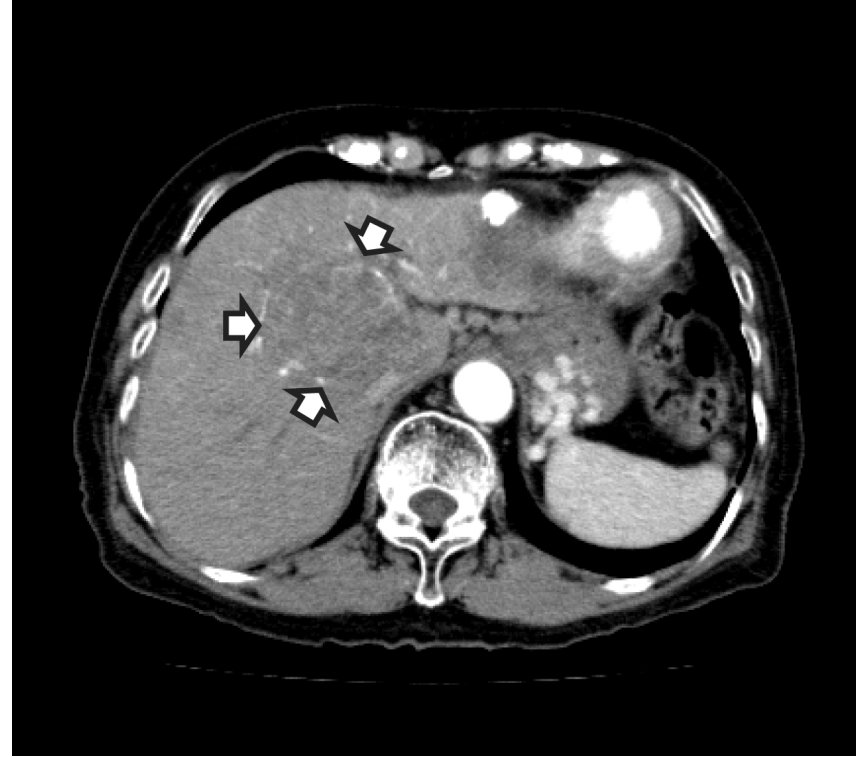

Figure 2: An enhanced CT scan of the abdomen showed a marked decrease in tumor enhancement (arrows), which indicated diminished blood flow on day three.

Sorafenib was discontinued at once, but the patient progressed to liver failure and died two weeks later.

\section{DISCUSSION}

This case shows two critical implications of sorafenib administration for clinicians. First, the possible associations between hepatic encephalopathy and sorafenib have been reported, [3-5] and there have recently been several cases of serious adverse events leading to death. Furthermore, hepatic encephalopathy was reported in 34 of 2375 (1.4\%) in Japanese patients in a blue letter by Bayer, which was higher than that in other countries. Thus, it should be investigated whether there are any differences in host factors or underlying liver diseases between Japanese and other ethnicities. Additionally, although sorafenib was administered for only three days, a clear decrease in tumor enhancement on the CT was evident. There have been no reports of such rapid changes in a patient with HCC treated with sorafenib to date. It has been suggested that sorafenib may exert beneficial effects through the inhibition of Raf serine/threonine kinases and tyrosine kinase receptors involved in tumor growth and angiogenesis [6]. Sorafenib clearly had strong antiangiogenic effects in our patient, but its mechanism is not precisely known.

\section{CONCLUSION}

As hepatic encephalopathy is a life-threatening complication that may develop quickly, clinicians should be aware of this adverse event when using sorafenib for HCC, especially when it is concomitantly diagnosed with Child-Pugh A. In particular, when a rapid decrease in tumoral blood flow is evident on CT scan, patients should be followed carefully for this possibility.

$* * * * * * * * *$

Kimura T, Umemura T, Ichijo T, Yamamura N, Tanaka E. Severe hepatic encephalopathy and decrease in enhancement of hepatocellular carcinoma treated with sorafenib. International Journal of Case Reports and Images 2010;1(4):16-18.

\section{$* * * * * * * * *$}

doi:10.5348/ijcri-2010-12-12-CI-4

\section{Author Contributions}

Takefumi Kimura - Conception and design, Acquisition of data, Analysis and interpretation of data, Drafting the article, Final approval of the version to be published

Takeji Umemura - Conception and design, Analysis and interpretation of data, Drafting the article, Final approval of the version to be published

Tetsuya Ichijo - Analysis and interpretation of data, Critical revision of the article, Final approval of the version to be published

Nobuyoshi Yamamura - Analysis and interpretation of data, Critical revision of the article, Final approval of the version to be published

Eiji Tanaka - Analysis and interpretation of data, Critical revision of the article, Final approval of the version to be published

\section{Guarantor}

The corresponding author is the guarantor of submission.

\section{Conflict of Interest}

Authors declare no conflict of interest.

\section{Copyright:}

(C) Takefumi Kimura et al. 2010; This article is distributed under the terms of Creative Commons attribution 3.0 License which permits unrestricted use, distribution and reproduction in any means provided the original authors and original publisher are properly credited. (Please see www.ijcasereportsandimages.com /copyright-policy.php for more information.)

\section{REFERENCES}

1. Llovet JM, Ricci S, Mazzaferro V, Hilgard P, Gane $\mathrm{E}$, Blanc JF, et al. Sorafenib in advanced 
hepatocellular carcinoma. $\mathrm{N}$ Engl $\mathrm{J}$ Med 2008;359(4):378-90.

2. Govindarajan R, Adusumilli J, Baxter DL, ElKhoueiry A, Harik SI. Reversible posterior leukoencephalopathy syndrome induced by RAF kinase inhibitor BAY 43-9006. J Clin Oncol 2006;24(28):e48.

3. Richly H, Schultheis B, Adamietz IA, Kupsch P, Grubert M, Hilger RA, et al. Combination of sorafenib and doxorubicin in patients with advanced hepatocellular carcinoma: results from a phase I extension trial. Eur $\mathrm{J}$ Cancer 2009;45(4):579-87.

4. Marks AB, Gerard R, Fournier P, Coupe P, Gautier S. Sorafenib-induced hepatic encephalopathy. Ann Pharmacother 2009;43(12):2121.

5. Worns MA, Weinmann A, Pfingst K, Schulte-Sasse C, Messow CM, Schulze-Bergkamen $\mathrm{H}$, et al. Safety and efficacy of sorafenib in patients with advanced hepatocellular carcinoma in consideration of concomitant stage of liver cirrhosis. J Clin Gastroenterol 2009;43(5):489-95.

6. Wilhelm SM, Carter C, Tang L, Wilkie D, McNabola A, Rong $\mathrm{H}$, et al. BAY 43-9006 exhibits broad spectrum oral antitumor activity and targets the RAF/MEK/ERK pathway and receptor tyrosine kinases involved in tumor progression and angiogenesis. Cancer Res 2004;64(19):7099-109. 